\title{
Productive response of Macabeo varietie in two locations of Spain
}

\author{
Amelia Montoro $^{1 *}$, Irene Torija ${ }^{1}$, Luis A. Mancha ${ }^{2}$, Daniel Moreno ${ }^{2}$ y David Uriarte ${ }^{2}$ \\ ${ }^{1}$ ITAP-FUNDESCAM, Polígono Campollano, Av. Segunda 61, 02007 Albacete, Spain \\ ${ }^{2}$ CICYTEX, Finca La Orden, Ctra. A-V, km 372, Guadajira, Badajoz, Spain
}

\begin{abstract}
The work was carried out on Vitis vinifera, L. (cv. Macabeo) grafted onto 110 Ritcher rootstock and cultivated in two locations of the southern half of Spain: La Albuera (Badajoz) and Villarrobledo (Albacete), during 2016 and 2017. The soil of La Albuera is clay-loam texture, $1 \mathrm{~m}$ deep and $160 \mathrm{~mm} / \mathrm{m}$ available water capacity (AWC); respect to climate is warm, cool nights and very dry according to the classification of [1]. The Villarrobledo soil is $0.75 \mathrm{~m}$ deep, silty-clay-loam texture and $135 \mathrm{~mm} / \mathrm{m} \mathrm{AWC}$; the climate is very warm, cool nights and moderately dry climate. The study consisted in maintaining during two consecutive years and in both locations, the same hydric state of grapevine, which was evaluated by measurements of midday stem water potential, and comparing productive results obtained in the two places. Results derived from the analysis of yield components, as well as those derived of grape composition (total acidity, tartaric acid, malic acid, $\mathrm{pH}$, potassium and soluble solids) show little variation between locations, instead great interannual variation among the parameters studied, so the "year-variety" effect seems to influence much more to the final result than the "locality-variety", for the case under study.
\end{abstract}

\section{Introduction}

Terroir is concerned with the relationship between the characteristics of an agricultural product (quality, taste, style) and its geographic origin, which might influence these characteristics. The concept of terroir has been described as an interactive ecosystem which include the climate, soil, the vine, and human factors [2, 3]. From another point of view, [4] defined "Terroir" as a ubiquitous term in the comercial wine world.

It is clear that the genotype is a major source of differences in fruit composition [5]. Fruit composition changes over time during berry development and ripening as part of the grapevine's developmental program and is therefore under genetic control [6]. Although the effect of climate, soil and cultivar on berry development and berry composition cannot be separated [7], [8] and [9] found that the effect of climate was indeed the geatest, after which soil and cultivar followed.

Climate has been described by several authors as having a major influence on berry composition, highlighting temperature as one of the main factors $[10,11,12]$. In fact, weather differences among years, in addition to vineyard location rather than, say, within-vineyard differences in soil composition, are by far the strongest determinants of fruit composition and wine quality [6, 13].

Acids are among the main compounds that originate the grape berry, since they play a vital role in the production of quality wines as they ultimately determine the organoleptic and aesthetic character perceived in the wine. In addition, both the shelf-life and ageing potential is influenced since the physical, biochemical and microbial stability of the wine is determined by the levels of wine acidity $[7,14]$.
The aim of this study was to study the behavior of Vitis vinifera cv. Macabeo in two locations across two vintages.

\section{Material and methods}

\subsection{Locations and soil}

The study was carried out during 2016 and 2017 in two commercial vineyards (Vitis vinifera cv. Macabeo) located in different province:

1 Albacete $(\mathrm{AB})$ (southeast of central area of Spain). The grapevine is located in Villarrobledo $\left(39^{\circ} 15^{\prime} \mathrm{N}, 2^{\circ} 40^{\prime} \mathrm{W}\right.$ $714 \mathrm{~m}$ altitude). The silty-clay-loam texture soil and 0.75 $\mathrm{m}$ deep of the experimental site was characterized by a available water capacity (AWC) of $135 \mathrm{~mm} / \mathrm{m}$.

2 Badajoz (BA) (southwest of central area of Spain). The grapevine is located in La Albuera $\left(38^{\circ} 42^{\prime} \mathrm{N}, 6^{\circ} 50^{\prime} \mathrm{W}, 253\right.$ $\mathrm{m}$ altitude). The clay-loam texture soil, $1 \mathrm{~m}$ deep and 160 $\mathrm{mm} / \mathrm{m}$ AWC.

\subsection{Plantations}

The experiment was performed on grapevines of similar years old (5-6 for $\mathrm{AB}$ and 6-7 for BA). Both vineyards were grafted to 110 Richter rootstock. The spacing followed a $3.10 \mathrm{~m} \mathrm{x} 2 \mathrm{~m}$ square pattern in $\mathrm{AB}$ and $2.9 \mathrm{~m}$ $\mathrm{x} 1.4 \mathrm{~m}$ in BA.

The experiment was realized in micro-plots in three replicate blocks, each block having three rows of 24 vines, in Albacete and six rows of 60 vines in Badajoz.

Vines were drip-irrigated. Both plots were managed according to commercial practices.

\subsection{Climatic description}


Meteorological variables during the experiment were measured with two automated weather station located over the trial plot in La Albuera and close to the experimental plot in Villarrobledo. All sensors were located between 1.5 and $2 \mathrm{~m}$ above the soil surface and weather data were registered in $15 \mathrm{~min}$, hourly and daily time steps. Variables measured were: air temperature, relative humidity, wind speed, wind direction, shortwave radiation, longwave radiation and rainfall. Reference evapotranspiration $\left(\mathrm{ET}_{0}\right)$ values were calculated with the daily and hourly time step FAO56 Penman-Monteith (FAO56 P-M) equation [15] using the recorded meteorological variables.

The aridity index is semiarid (Mediterranean Type) in both grapevines according to [16]. The climate is very warm, cool nights and moderately dry climate in Villarrobledo; and warm, cool nights and very dry in La Albuera, according to the classification of [1].

\subsection{Irrigation regime and measurements}

The irrigation regime consisted in applying the $30 \%$ of $\mathrm{ET}_{0}$ from veraison to harvest.

The main parameters measured in both vineyards were: phenological stage [17]; leaf area index (LAI), obtained with allometric measures of shoot length in Albacete and leaf nerve length in Badajoz related in both cases with leaf area; and midday stem water potential ( $\Psi s$ ), measured with a pressure chamber technique [18]. Stem water potential was determined around solar noon on exposed and bagged leaves covered with aluminum foil for at least $45 \mathrm{~min}$ before taking the measurements and stomata density were measured after veraison on fully developed leaves. Water stress integral was calculated from budburst to harvest according to [19].

It was tried that four vintages were realized at a similar level of total soluble solids (TSS) (close to $22^{\circ} \mathrm{Brix}$ ). This level of technological ripeness was chosen to ensure that a potential unripe character of the must did not influence the rest of parameters and they could be comparable. Due to logistical reasons and sampling variability, the vineyards could not always be harvested at the desired TSS level. Table 5 provides an indication of the differences in the sugar content between vintages and between sites.

At harvest, the fruit of central lines were weighed in the field. The samples were transported from the field to the laboratory. In the laboratory, the bunches and 100 berry sample picked from the left, right, top and bottom of the bunch were counted and weighed. After weighing, $2000 \mathrm{~g}$ of each treatment and repetition they were refrigerated to $4^{\circ} \mathrm{C}$ and transported to laboratory for determining the total soluble solids (TSS), $\mathrm{pH}$, titratable acidity, tartaric acid, malic acid and $\mathrm{K}$.

Statistical analysis was performed using IBM SPSS Statistics v.19 computer software (IBM SPSS Statistics, 2012). Analysis of variance (ANOVA) was carried out to test the degree to which two or more groups vary or differ in the experiment. The significance level of the correlation coefficient was determinate at $5 \%$.

\section{Results and discussion}

Table 1 shows the atmospheric evaporative demand and water applied from sprouting to harvest for two years and two locations. Highlights the $\mathrm{ET}_{0}$ of 2016 that it was about $10 \%$ higher than 2017 for both locations and the rainfall so different $(40 \%)$ in Badajoz for the two years of study.

Table 1. Reference evapotranspiration, rainfall, irrigation and total water applied.

\begin{tabular}{lccccc} 
Location & Year & $\begin{array}{c}\text { ET0 } \\
(\mathbf{m m})^{(*)}\end{array}$ & $\begin{array}{c}\text { Rainfall } \\
(\mathbf{m m})^{(*)}\end{array}$ & $\begin{array}{c}\text { Irrigation } \\
(\mathbf{m m})^{(*)}\end{array}$ & $\begin{array}{c}\text { Total water applied } \\
(\mathbf{m m})^{(*)}\end{array}$ \\
\hline Albacete & 2016 & 814 & 98 & 57 & 154 \\
\cline { 2 - 6 } & 2017 & 780 & 83 & 64 & 147 \\
\hline Badajoz & 2016 & 835 & 154 & 56 & 210 \\
\cline { 2 - 6 } & 2017 & 721 & 61 & 53 & 114 \\
\hline (*) From sprouting to harvest & & & &
\end{tabular}

Figure 1 shows the average, máximum and mínimum temperatura during the main periods of crop in 2016 (a) and 2017 (b). Despite having a similar climate according to [16] and [1], differences in temperature between the two sites under study are observed, reaching the highest values Badajoz. These differences are much more marked on the day of the harvest (Figure 2).

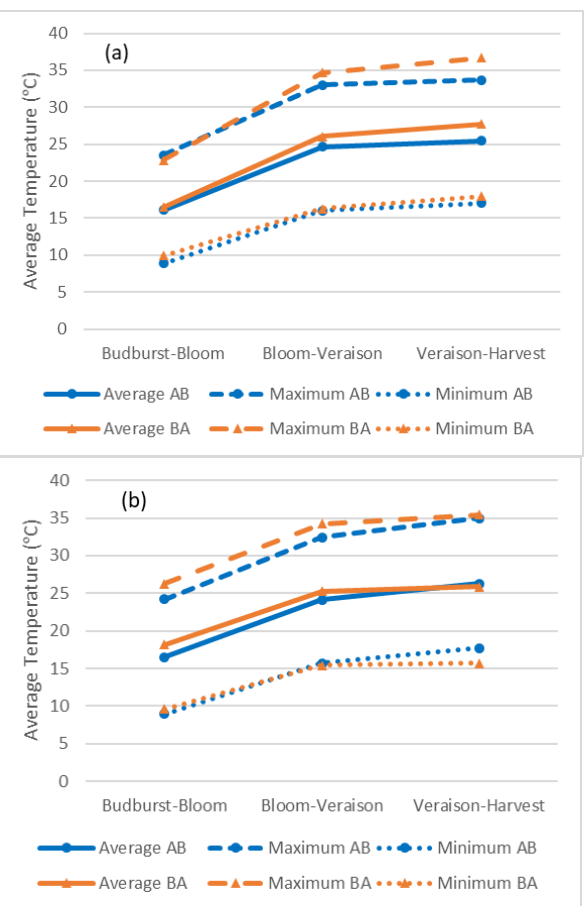

Figure1: Temperature (average, maximum and minimum) from budburst to bloom, bloom to veraison and veraison to harvest in Albacete (AB) and Badajoz (BA) for 2016 (a) and 2017 (b). 


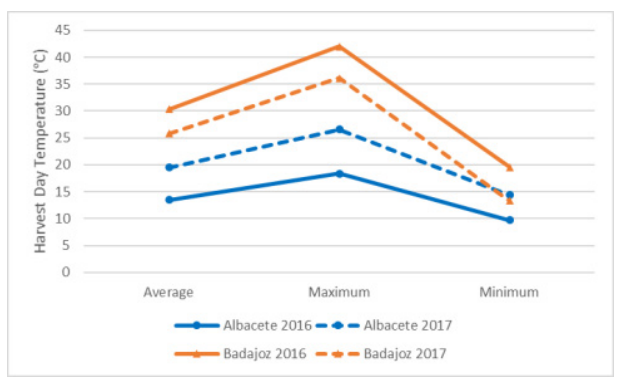

Figure 2. Harvest day temperature (average, maximum and minimum) in Albacete and Badajoz for 2016 and 2017.

Main phenological growth states are shown in table 2 . Albacete and Badajoz presented an advance in 2017 with respect to 2016, in all its phenological stages from sprouting. Phenology is considered as the first biological indicator of climate [20], in this sense, the thermal integral analysis, that is used as one of the main criteria to assess the suitability of a cultivar to a location [21], is represented in figure 3 . Budburst and flowering happened with the same accumulated temperature in both locations and the two years of study, instead the veraison was reached with higher temperature in Badajoz that in Albacete.

Table 2. Date of phenological growth stages

\begin{tabular}{ccc|cc} 
& \multicolumn{3}{c}{ Phenological Growth Stages Date } \\
\cline { 2 - 5 } & \multicolumn{2}{c}{ Albacete } & \multicolumn{2}{c}{ Badajoz } \\
\cline { 2 - 5 } & $\mathbf{2 0 1 6}$ & $\mathbf{2 0 1 7}$ & $\mathbf{2 0 1 6}$ & $\mathbf{2 0 1 7}$ \\
\hline Budburst & 16-Apr & 12-Apr & 11-Apr & 10-Apr \\
\hline Flowering & 12-Jun & 25-May & 6-Jun & 22-May \\
\hline Veraison & 26-Jul & 11-Jul & 1-Aug & 17-Jul \\
\hline Harvest & 14-Sep & 29-Aug & 5-Sep & 16-Aug \\
\hline
\end{tabular}

An indication of the variability of the phenological dates per vintage and per cultivar is provided in Table 3 . It is clear the great variation in the data, not only between the years, also between the locations, and within the year. The length of one interval per vintage does not dictate the length of the following interval in that vintage. Similar results were found by [7].

Table 3. Days between the major phenological stages in Albacete and Badajoz for 2016 and 2017.

\begin{tabular}{lrrrr} 
& \multicolumn{2}{c}{ Albacete } & \multicolumn{2}{c}{ Badajoz } \\
\cline { 2 - 5 } & $\mathbf{2 0 1 6}$ & $\mathbf{2 0 1 7}$ & $\mathbf{2 0 1 6}$ & $\mathbf{2 0 1 7}$ \\
\hline Budburst-Bloom & 57 & 43 & 56 & 42 \\
Bloom-Veraison & 44 & 47 & 56 & 56 \\
Veraison-Harvest & 50 & 49 & 35 & 30 \\
\hline Budburst-Harvest & 151 & 139 & 147 & 128 \\
\hline
\end{tabular}

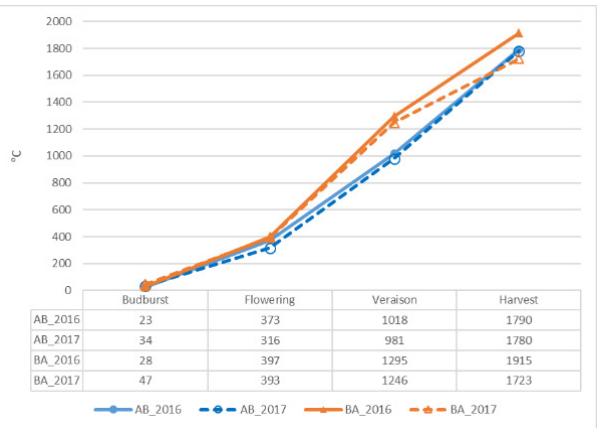

Figure 3. Thermal integral of grapevine for both locations in 2016 and 2017.

Leaf area index (LAI) in 2016 was higher than in 2017 and it was similar in both locations (Figure 4).

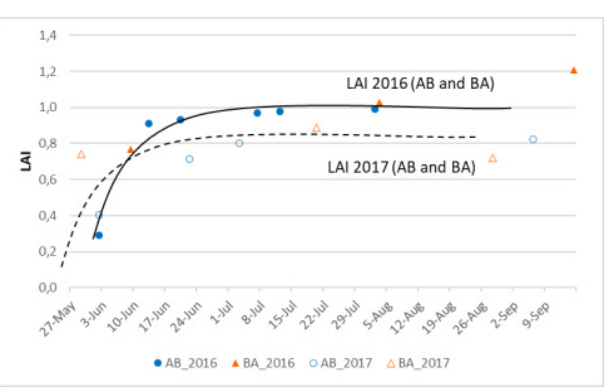

Figure 4. Leaf area index

The values of $\Psi$ s are shown in Figure 5 for 2016 (a) and 2017 (b) for both locations. In general, the beginning of the cycle in 2016 was less stressed than in 2017, however, the harvest occurred in 2016 with more negative potential values than in 2017 , for both locations. Highlights the recovery of potential in Albacete after the first irrigation, not so in the case of Badajoz. Despite this, the water stress integral was similar in both locations and for two years of study (Table 4). 


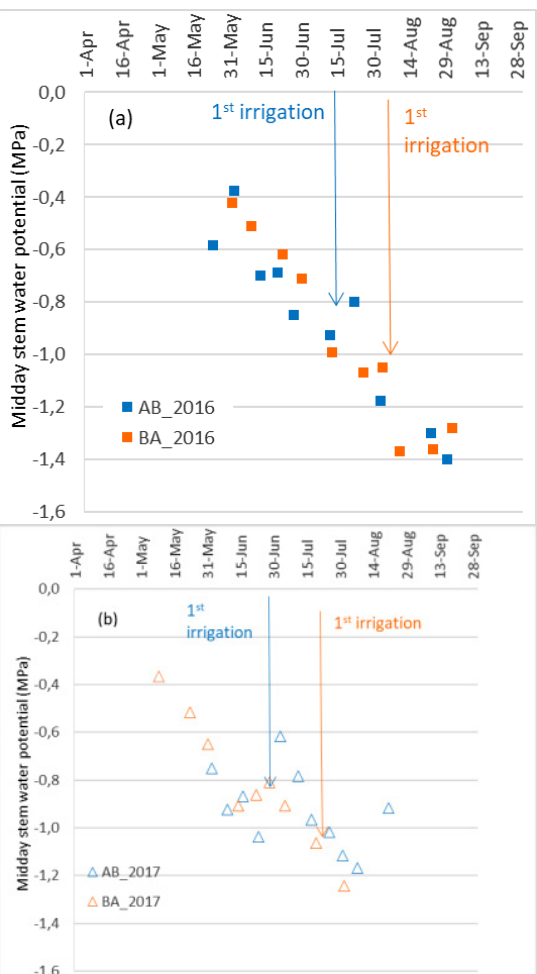

Figure 5. Midday stem water potential of grapevine for both locations in 2016 (a) and 2017 (b)

Table 4. Water stress integral from budburst to harvest.

\begin{tabular}{lcc} 
Location & Year & $\begin{array}{c}\text { Water stress } \\
\text { integral }\end{array}$ \\
\hline Albacete & 2016 & 57,43 \\
\hline Badajoz & 2017 & 58,62 \\
\hline & 2016 & 57,83 \\
\hline & 2017 & 59,91 \\
\hline
\end{tabular}

Referent to yield, there were significant differences in yield in Albacete between 2016 and 2017 (Figure 6), not so in Badajoz and between Badajoz and 2017 in Albacete. This should be due to the production is defined in two years and 2015 (the year previous to experiment) the plot in Albacete was irrigated by the farmer without taking into account the water status of the plants. The yield difference was determined mainly by the bunches weight (Figure 7), and the number of berries since there was no significant difference in the weight of the berry (Figure 8) and the bunches number (Figure 9) was similar in both years. This agrees with that reported in previous studies [22] and it is true for both the variation between cultivars and the variation between growing seasons for the same cultivar [6].

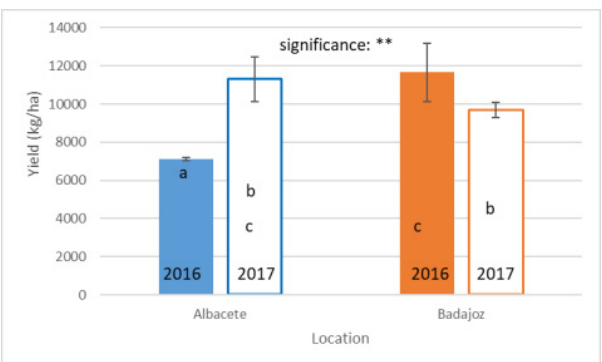

Figure 6. Yield of grapevine for both locations in 2016 and 2017.

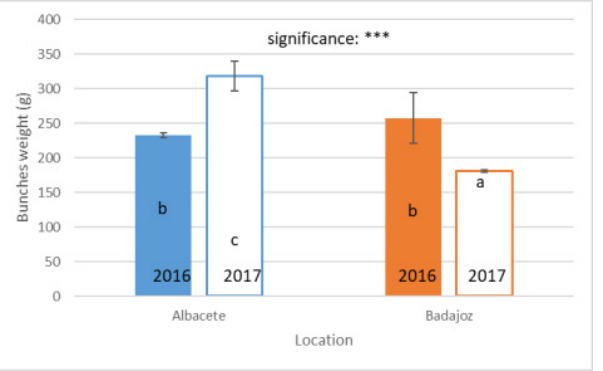

Figure 7. Bunches weight of grapevine for both locations in 2016 and 2017.

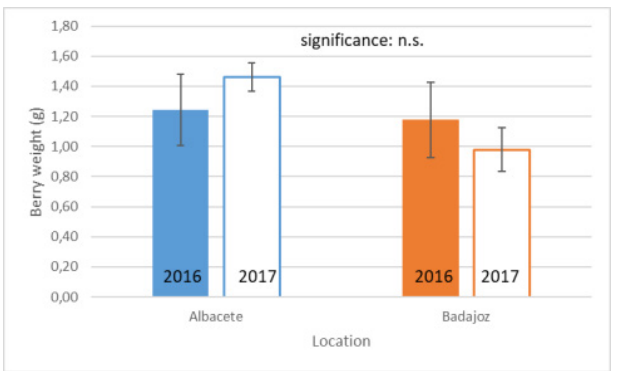

Figure 8. Berry weight of grapevine for both locations in 2016 and 2017 .

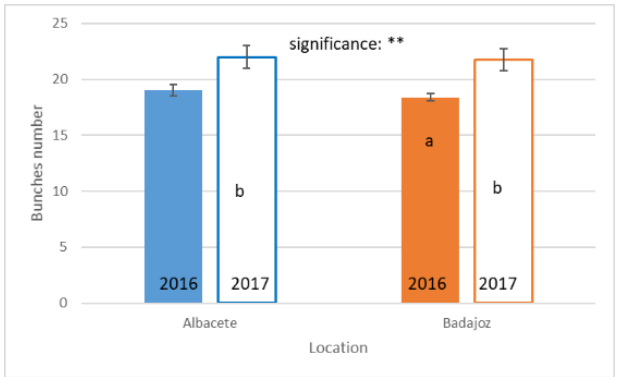

Figure 9. Bunches number of grapevine for both locations in 2016 and 2017. 
Average technological maturity parameters at harvest are shown in Table 5. The location did not influence technological maturity except in malic acid (Figure 10 and Table 6), whereas the year effect seemed to have a greater influence in total acidity, tartaric acid and in the potassium content of the must (Table 6).

Table 5. Technological maturity parameters of must at at harvest for both locations in 2016 and 2017.

\begin{tabular}{lccc} 
& & \multicolumn{2}{c}{ Location } \\
& Year & Albacete & Badajoz \\
\hline Total acidity & 2016 & 4,17 & 4,22 \\
(g/l Tart. Ac.) & 2017 & 4,55 & 5,38 \\
\hline Tartaric acid & 2016 & 6,18 & 6,23 \\
(g/l) & 2017 & 5,84 & 4,81 \\
\hline Malic acid & 2016 & 1,27 & 0,65 \\
(g/l) & 2017 & 1,63 & 0,31 \\
\hline $\mathbf{p H}$ & 2016 & 3,7 & 3,6 \\
& 2017 & 3,8 & 3,6 \\
\hline Potasium & 2016 & 1,22 & 0,98 \\
(g/l) & 2017 & 1,23 & 1,52 \\
\hline${ }^{\circ}$ Brix & 2016 & 22 & 20 \\
& 2017 & 26 & 23 \\
\hline
\end{tabular}

The differences found in acids can be due to the different temperatures between locations and years. The effect of temperature on the organic acid content of the must is widely discussed with higher temperatures in general being associated with lower quantities of organic acids present in the juice, and lower temperatures during ripening associated with higher quantities, specifically in the case of malic acid [7].

Malic and tartaric acid has a definite synthesis period up until veraison, after which the content of tartaric acid remains constant in the berry and the content of malic acid decreases until harvest due to mainly respiration. The effect of climate, in particular temperature, on the metabolism of malic and tartaric acid, and the subsequent breakdown of malic acid after veraison, is well studied and understood. Although temperature has been found to have little or no effect on the tartaric acid content of the berries, the malic acid content reveal great changes according to the seasonal climatic differences [8, 10, 23]. Higher temperatures and higher respiration rates usually found in light exposed berries are in general attributed to lower malic acid levels [24].

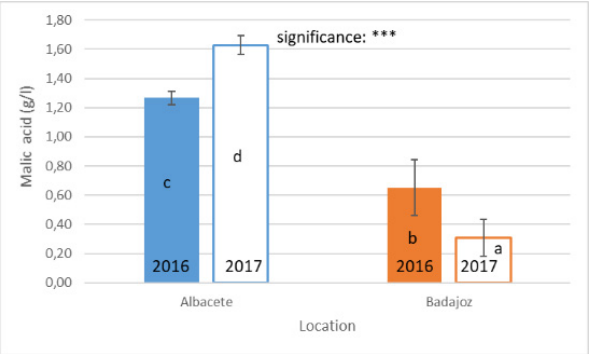

Figure 10. Malic acid of must for both locations in 2016 and 2017.
Table6. Results of analysis of variance for technological maturity parameters.

\begin{tabular}{lcc} 
Parameter & Location & Year \\
\hline Total acidity & n.s. & $* *$ \\
\hline Tartaric acid & n.s. & $*$ \\
\hline Malic acid & $* * *$ & n.s. \\
\hline pH & n.s. & n.s. \\
\hline Potasium & n.s. & $*$ \\
\hline Total soluble solids & n.s. & n.s. \\
\hline$*<0.05, * *<0.01, * * *<0.001$, n.s.: non significance.
\end{tabular}

\section{Conclusion}

Results show little variation between locations, instead great interannual variation among the parameters studied, so the "year-variety" effect seems to influence much more to the final result than the "locality-variety", for the case under study. This is mainly due to the variability of malic acid between vintages and according to the cultivar as the influence is not that noticeable for tartaric acid, glimpsing the effect of temperature on malic acid.

\section{References}

1. J. Tonietto, A. Carbonneau. Agricultural and Forest Meteorology, v.124, p.81-97 (2004)

2. M. Matthews. Terroir and other myths of winegrowing. University of California Press (2015).

3. G. Seguin. Experientia 42, 861-873 (1986)

4. G. Seguin. L. Fuller-Perrine (ed.) Proceedings of the Symposium on maritime Climate Winegrowing. Geneva, NY: Department of Horticultural Sciences, Cornell University (1988)

5. Z.W. Dai, N. Ollat, E. Gomes, S. Decroocq, J.P. Tandonnet, L. Bordenave et al. American Journal of Enology and Viticulture 62, 413-425 (2011)

6. M. Keller. The Science of Grapevines. USA (2015)

7. Z.A. Coetzee. Site and vintage response of malic and tartaric acid in Vitis vinifera L. cv's Cabernet Sauvignon and Sauvignon blanc. Theses in Stellenbosch University. Department of Viticulture and Oenology, Faculty of AgriSciences. (2013).

8. C. Van Leeuwen, P. Friant, X. Choné, O. Tregoat, S. Koundouras, D. Dubourdieu. American Journal of Enology and Viticulture 55 (3), 207-217 (2004)

9. G.Jones. https://www.guildsomm.com/public_content/featur es/articles/b/gregory jones/posts/climate-grapesand-wine (2015)

10. B. G. Coombe. Acta horticulturae 206, 23-35 (1987)

11. D.I. Jackson, P.B. Lombard. American Journal of Enology and Viticulture 44 (4), 409-430 (1993)

12. J.J. Hunter, V. Bonnardot. South African Journal of Enology and Viticulture 32 (1), 137-154 (2011)

13. A.G. Reynolds, G. Taylor, C. de Savigny. American Journal of Enology and Viticulture 64 180-194 (2013) 
14. R. Boulton. American Journal of Enology and Viticulture 31 (1), 76-80 (1980)

15. R.G. Allen, L.S. Pereira, D. Raes, M. Smith. FAO Irrigation and Drainage, paper no. 56 (1998)

16. E. De Martonne. La Meteorologie, vol. 2, pp. 44958 (1926)

17. M. Baggiolini, M. Rev. Rom. Agr. Viticult. 8, 4-6 (1952)

18. P.F. Scholander, E.D. Bradstreet, E.A. Hemmingsen, H.T. Hammel . Science 148 (3668), 339-346 (1965)

19. B.J. Myers. Tree Physiology 4, 315-323 (1988)

20. A. Menzel, T.H. Sparks, N. Estrella,E. Koch, A. Aasa, R. Ahas, K. Alm-Kübler, P. Bissolli, O. Braslavská, A. Briede, F.M. Chmielewski, Z. Crepinsek, Y. Curnel, A. Dahl, C. Defila, A. Donnelly, Y. Filella, K. Jatczak, F. Måge, A. Mestre, O. Nordli, J. Peñuelas,P. Pirinen, V. Remišová, H. Scheifinger, M. Striz, A. Susnik, A.J.H. Van Vliet, F.E. Wielgolaski, S. Zach, A. Zust. Global Change Biology 12, 1969-1976. (2006)

21. J. Gladstones. Viticulture and Environment. Winetitles. Adelaide (1992)

22. O. Currle, O.Bauer, W. Hofäcker, F. Schumann, W. Frisch. Biologie der Rebe. Meininger, Germany (1983)

23. A.J. Winkler. General Viticulture. University of California Press (1962)

24. A.N. Lakso, W.M. Kliewer. American Journal of Enology and Viticulture 29 (3), 145-149 (1978) 